\title{
The Impact of Dialect Diversity on the Economy of Ethnic Areas_-Taking Sichuan Province as an Example
}

\author{
Wang Simin ${ }^{1, a^{*}}$, Li Jiayuan ${ }^{2, b}$, Guo Wengjie ${ }^{3, \text { c }}$, Yang Huilin ${ }^{4, d}$, Fei Yang, e \\ ${ }^{1}$ Sichuan Agricultural University, Dujiangyan, Chengdu, Sichuan, China \\ ${ }^{2}$ Sichuan Agricultural University, Dujiangyan, Chengdu, Sichuan, China \\ ${ }^{3}$ Sichuan Agricultural University, Dujiangyan, Chengdu, Sichuan, China \\ ${ }^{4}$ Sichuan Agricultural University, Dujiangyan, Chengdu, Sichuan, China \\ ${ }^{5}$ Sichuan Agricultural University, Dujiangyan, Chengdu, Sichuan, China
}

\begin{abstract}
Based on the methods of literature survey, interview survey and questionnaire survey, this paper selects Xiaojin, Danba, Kangding, Luding, Puge and Butuo County as the survey sites of multi-ethnic areas in Sichuan Province. After obtaining the first-hand data and data of local dialect usage, family language habits and family economic conditions, it empirically analyzes the relationship between dialect diversity and economic income and comes to a conclusion that in the multi-ethnic areas of Sichuan Province, dialect diversity has a significant negative impact on the level of economic income. On the basis of deepening the understanding of the relevance between language and economy, this paper provides some reference for the government to carry out reasonable language planning in ethnic areas.
\end{abstract}

\section{PREFACE}

Sichuan Province is a multi-ethnic province in Southwest China, covering a total area of 486000 square kilometers, including three autonomous prefectures and four autonomous counties, with 183 county-level divisions, including 51 Minority Counties, covering more than $60 \%$ of the total area of the province. There are 56 ethnic minorities and 12 ethnic minorities in the province, of which the number of ethnic minorities accounts for $6.47 \%$ of the total population of the province. The multi-ethnic areas are often distributed in the mountainous, hilly and plateau terrain complex belt, with poor traffic convenience and backward economic level. Diversified ethnic distribution leads to diversified ethnic languages. According to the classification of language genealogy, except for the languages used by Manchu and Mongol, the national languages distributed in various regions of Sichuan province belong to the Sino Tibetan language family, with a total of 21 kinds. However, in March of 2018, the Provincial Department of education, the poverty alleviation Bureau and the language Working Committee issued a document on "the implementation plan of Sichuan Province to promote the national common language and characters to help poverty alleviation", which focused on more than 80 poverty-stricken counties, filing and Lika poverty-stricken villages and poor households in Sichuan Province, including Tibetan area, Liangshan Prefecture, Aba Prefecture, Ganzi Prefecture and three districts.
Relevant departments actively cooperate, vigorously popularize the national common language, and strive to do a good job in the project of "pushing the general out of poverty". Therefore, language has become an important factor in the process of economic development Whether diversified dialects can play an invisible role in the economic and trade exchanges between regions? In other words, whether the more common language can play a role as a lubricant in the economic activities such as commodity exchange and service trade has become an irrecoverable factor in the process of economic development Avoid problems. Based on the investigation of dialect diversity in multi-ethnic areas of Sichuan Province, the related literature and the first-hand statistics, this paper will study whether language diversity will affect economic growth and the degree of its impact on economic growth.

\section{LITERATURE REVIEW}

China is a multi-ethnic country with rich language resources in history. According to incomplete data, of the 55 ethnic minorities in China, more than 120 kinds of ethnic languages have been found. As an important communication tool, language is the main expression of people's communication. It plays a role in the preservation and transmission of human civilization and is one of the important characteristics of a nation. In addition, German scholar Dustmann shows that there is an important relationship between German ability and the

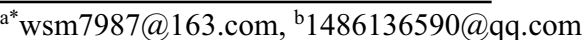

c164712699@qq.com, d1602578046@qq.com

e984408672@qq.com
} 
working class's remuneration and working level through research [1]. Beenstock, Chiswick and repetto have also confirmed that there is a positive correlation between language level and migrant income in similar studies conducted in Israel[2]. Zhang Weiguo, a domestic scholar, also pointed out that language is a kind of human capital[3]. He believed that language plays an important role in determining labor market employment and people's labor income. Investing in language skills can bring short-term and long-term benefits, especially in multi-ethnic areas. Therefore, there is an inseparable relationship between language and economy, and the optimization of language is of great significance to the improvement of economic level. However, in the face of diversified languages, scholars Mo Zaishu [4] pointed out that different languages have different contribution values to economic development, and different languages have different economic values. Lei Xiaolan [5] believes that a common and strong language can reduce the cost of unnecessary information collection, analysis and exchange, enhance the trust of both sides of communication, reduce transaction risk, bring direct benefits to the user group and help expand the business types of indirect benefits. Based on the data of cities above prefecture level cities in China, $\mathrm{Xu}$ Xianxiang concluded that the higher the degree of dialect diversification, the lower the level of economic development [6]. However, in multi-ethnic areas, similar research is still relatively lacking. Whether diversified languages are hindering economic growth, especially in multi-ethnic areas, what kind of relationship between language diversity and economic growth will appear, and the degree of impact on economic level. The solution of these problems will help to better balance the relationship between economic development and the protection of national cultural diversity, which is of great significance to the economic development and planning of ethnic areas and the formulation of language policies.

\section{DIALECT DIVERSITY AND ECONOMIC GROWTH}

\subsection{Theoretical Model}

According to the statistics of the dictionary of Chinese dialects, there are 17 dialects and 105 sub dialects in China. From the perspective of languages used by all ethnic groups in Sichuan Province, Liu Huiqiang pointed out that the ethnic minorities in Sichuan Province, except Hui and Manchu, all have their own languages [7]. From the perspective of economic data, although the "three prefectures" of Sichuan Province account for $60.3 \%$ of the total area of the province, the total economic volume is only $5.3 \%$ of the province. The problem of unbalanced development is very prominent. In recent years, the government has actively organized the work of "language poverty alleviation", and more attention has been paid to the impact of language on economy. According to the data at the end of 2018, the popularity rate of Mandarin in Sichuan Province has increased to $80.31 \%$, and the number of Mandarin tests ranks the second in the country.
However, according to the household statistics of this survey, the proportion of the observed families in ethnic areas using Mandarin at home is less than $30 \%$, and the problem of language diversity in multi-ethnic areas is still worthy of attention.

This paper first puts forward the hypothesis: the more diverse the dialect, the lower the economic level.

In macroeconomic research, economists use production function to analyze the relationship between various factors and explain economic growth from the perspective of capital, labor, technological level and natural resources. According to the new theory of economic growth, the deeper power of economic growth is culture.

In order to further analyze the impact of language diversity on economic growth, this paper will build a model (1).

$$
\ln \mathrm{y}_{\mathrm{i}}=\alpha_{1}+\alpha_{2} L a n+X_{i} \psi_{i}+\varepsilon_{i}
$$

In this paper, LAN is used to express the number of sub dialects that the surveyed families are exposed to in their places of life. The minimum value of LAN is 1 . The more diverse the language, the greater the value of LAN. $\mathrm{y}$ represents the economic income of the family. ${ }^{\ln \mathrm{y}_{\mathrm{i}}}$ is the logarithm of the household income of the observation sample; LAN is the dialect diversity index of the region; $X_{\mathrm{i}}$ is a series of factors that don't change over time, including Dis-county, Edu, Type. Dis-county is the distance between the sample family and the county seat, calculated by the highway distance, and its unit is $\mathrm{km}$; Edu represents the education level of the main labor force in the sample family, the Edu value is between 1 and 5, the higher the Edu value is, the higher the education level is; Type is a virtual variable, indicating whether the type of household is urban or rural. $\varepsilon$ is the disturbance term. $\alpha_{2}$ is the coefficient of LAN value in formula (1), which is used to measure the influence direction and degree of dialect diversity on economic growth, If the theoretical hypothesis holds, then $\alpha_{2}<0$.

\subsection{Empirical Analysis}

This paper selects Xiaojin, Danba, Kangding, Luding, Puge and Butuo counties as the survey sites of multi-ethnic areas by consulting relevant documents and materials. In July of 19 years, I had field interview and questionnaire survey to obtain the first-hand data and data of local dialect use, family language use habits and family economic status. The number of effective observations in this sampling survey is 173 . Of the 173 families surveyed, 73 were in multi-ethnic areas or "dialect complex counties", accounting for $42.2 \%$ of the total sample. The remaining 100 families came from non multi-ethnic areas or "dialect complex counties". Table 1 is a simple descriptive statistics of dialect diversity. As shown in Table 1, the average value of LAN in 173 families is 1.85 , the minimum value is 1 , and the maximum value is 4 . That is to say, the number of sub dialects that families touch at the same time in daily life is up to 4 . 
Table 1 Simple description statistics of dialect diversity

\begin{tabular}{ccccccccc}
\hline Project & Mean & Minimum & 25\%quantile & $50 \%$ quantile & $75 \%$ quantile & Maximum & $\sigma$ & Quantity \\
\hline Lan & 1.85 & 1 & 1 & 2 & 2 & 4 & 0.9025 & 173 \\
\hline
\end{tabular}

Table 2 shows the results obtained after regression with formula (1). The regression coefficient of LAN is always less than zero and remains significant, so the

Table 2 Influence of dialect diversity on economic development level

\begin{tabular}{|c|c|c|c|c|}
\hline \multirow{2}{*}{ Variable } & (1) & (2) & (3) & (4) \\
\hline & \multicolumn{4}{|c|}{$\ln y$} \\
\hline Lan & $\begin{array}{c}-0.1657938^{* * *} \\
(0.0572411)\end{array}$ & $\begin{array}{c}-0.1547854 * * * \\
(0.0546876)\end{array}$ & $\begin{array}{c}-0.1449492 * * \\
(0.056157)\end{array}$ & $\begin{array}{c}-0.1276836^{* *} \\
(0.0573852)\end{array}$ \\
\hline Dis-county & $\begin{array}{l}- \\
-\end{array}$ & $\begin{array}{l}- \\
-\end{array}$ & - & $\begin{array}{l}-0.0085421 * \\
(0.0050899)\end{array}$ \\
\hline Constant & $\begin{array}{l}11.43591 * * * \\
(0.0948188)\end{array}$ & $\begin{array}{l}11.28165 * * * \\
(0.1042818)\end{array}$ & $\begin{array}{c}11.09051 * * * \\
(0.155457)\end{array}$ & $\begin{array}{l}11.20968 * * * \\
(0.1617883)\end{array}$ \\
\hline Type & $\begin{array}{l}- \\
-\end{array}$ & $\begin{array}{c}0.2790803 * * * \\
(0.0825903)\end{array}$ & $\begin{array}{c}0.2289003^{* *} \\
(0.08908)\end{array}$ & $\begin{array}{c}0.1487397 \\
(0.0986887)\end{array}$ \\
\hline Edu & $\begin{array}{l}- \\
-\end{array}$ & $\begin{array}{l}- \\
-\end{array}$ & $\begin{array}{l}0.065171^{* *} \\
(0.031595)\end{array}$ & $\begin{array}{c}0.0531841^{*} \\
(0.0316479)\end{array}$ \\
\hline$R^{2}$ & 0.0669 & 0.1251 & 0.1421 & 0.1612 \\
\hline Observations & 173 & 173 & 173 & 173 \\
\hline
\end{tabular}

Note: the regression results in the above table are estimated by OLS; in brackets are the robust standard errors corrected by white heteroscedasticity; $* * *$ indicates that the $\mathrm{p}$ value is less than $0.01, * *$ indicates that the $\mathrm{p}$ value is less than $0.05, *$ indicates that the $\mathrm{p}$ value is less than $0.1 ; \mathrm{R} 2$ is the unadjusted judgment coefficient.

The first column of Table 1 reports the results of one-way regression of LAN, which only introduces the diversity of dialects. At this time, the regression coefficient of LAN is -0.166 , which can pass the test of $1 \%$ significance level. This shows that for every unit of decline in dialect diversity, the economic income will increase by $16.6 \%$. Specifically, according to the descriptive statistics in Table 1, the maximum and minimum values of LAN are 4 and 1 respectively. If the diversity of urban dialects is eliminated, the maximum economic income can increase by $49.8 \%$ when other conditions remain unchanged. Columns $2-4$ in Table 1 report the regression results after gradually introducing relevant control variables. Specifically, columns 2-4 gradually introduce the virtual variable of residents type of sample families, the distance between the education level of the main labor force in the family and the distance between the family and the county. Column 5 of Table 1 reports the regression results after the introduction of these control variables at the same time. At this time, the regression coefficient of LAN is still a negative sign, $\alpha_{2}<0$. It can pass the statistical test with a significance level of $5 \%$. The absolute value is slightly smaller, from about 0.145 to 0.128 . It shows that if the diversity of dialects is eliminated and other conditions remain unchanged, the maximum economic income can be increased by about $38.4 \%$. As far as the control variables are concerned, the regression coefficient of the distance between the sample family and the county is about 0.00854 , which can pass the test with a significant level of $10 \%$. The unit is $\mathrm{km}$, that is, the closer the family is to the county, the higher the average economic income is. When other conditions remain unchanged, the average economic income will increase by $0.854 \%$ for every 100 $\mathrm{km}$ less distance. The minimum value of edu is 1 , the maximum value is 5, 1-5 represents the education level of none, primary school, junior high school, senior high school, University and above. As shown in Table 2, the regression coefficient of the education level of the main labor force in the family is about 0.0531 , which can pass the test with a significant level of $10 \%$. So if other conditions remain unchanged, the income of the main labor force in the family will increase by $5.31 \%$ for each additional level of education level.

All in all, the above regression results are consistent with the theoretical hypothesis expected in this paper. Dialect diversity has a significant negative impact on economic growth. In the above simulation scenario, if the dialect diversity is eliminated, the economic income can be increased by $49.8 \%$ at most. 
Table 3 impact of dialect diversity on economic development level by WLS estimation

\begin{tabular}{|c|c|c|c|c|}
\hline \multirow{2}{*}{ variable } & (1) & (2) & (3) & (4) \\
\hline & \multicolumn{4}{|c|}{$\ln y$} \\
\hline \multirow{2}{*}{ Lan } & $-0.2024081 * * *$ & $-0.1877923 * * *$ & $-0.1714562 * * *$ & $-0.159322 * * *$ \\
\hline & $(0.0515446)$ & $(0.0495069)$ & $(0.0497292)$ & $(0.0503952)$ \\
\hline \multirow{2}{*}{ Dis-county } & - & - & - & -0.0063949 \\
\hline & - & - & - & $(0.00469)$ \\
\hline \multirow{2}{*}{ Constant } & 11.50363 & 11.36808 & 11.17197 & 11.25124 \\
\hline & $(0.0827972)$ & $(0.0936148)$ & $(0.1343668)$ & $(0.1460899)$ \\
\hline \multirow{2}{*}{ Type } & - & $0.2261867 * * *$ & $0.172452 * *$ & 0.123293 \\
\hline & - & $(0.0729657)$ & $(0.0770631)$ & $(0.0849028)$ \\
\hline \multirow{2}{*}{ Edu } & - & - & $0.0634016^{* *}$ & $0.0564806^{*}$ \\
\hline & - & - & $(0.0314221)$ & $(0.0317508)$ \\
\hline$R^{2}$ & 0.0827 & 0.1351 & 0.1555 & 0.1647 \\
\hline Observations & 173 & 173 & 173 & 173 \\
\hline
\end{tabular}

Note: $* * *$ indicates that the $\mathrm{p}$ value is less than $0.01, * *$ indicates that the $\mathrm{p}$ value is less than $0.05, *$ indicates that the $\mathrm{p}$ value is less than $0.1 ; \mathrm{R}^{\wedge} 2$ is the unadjusted decision coefficient.

Considering the existence of heteroscedasticity, WLS estimation of the above model is carried out again in this paper. The results are shown in Table 3 . The first column of Table 3 is the regression results when the independent variable is only the dialect diversity LAN. The second and fourth columns are the regression results after the introduction of dummy variable of resident type of sample family, education level of main labor force in the family and distance between the family and the county based on the cited variable LAN. It can be seen that the regression coefficients of LAN are always negative and all pass the $1 \%$ significance test.

WLS estimation results show that Lan value is always negative and can pass the test of $1 \%$ significance level. That is to say, in the case of considering heteroscedasticity, the conclusion that dialect diversity has a significant negative impact on economic growth still holds. If we control the relevant variables, then eliminating the diversity of dialects can bring about $47.7 \%$ positive impact on economic income.

\section{Conclusion}

In the simulation of the above assumptions, by constructing regression model and estimating OLS and WLS, it can be concluded that dialect diversity in multi-ethnic areas of Sichuan Province has a significant negative impact on the economic income level of families. At present, the research on the economic relevance of dialects in China is still relatively scarce, especially in the multi language areas of ethnic minorities. On the one hand, these minority areas with rich language resources are facing the demands of poverty alleviation and economic development, and on the other hand, the problem of protecting ethnic cultural diversity is prominent. Dialect, as an important carrier of Chinese national culture, its inheritance is of course important, but under the market form of general economy, the diversity of dialect to a certain extent plays a restraining role in the regional economy. Therefore, through this analysis, this paper suggests that the government should pay attention to the economic value of language, actively promote the "promotion and poverty alleviation", do bilingual education and language planning in many ethnic areas, while protecting local dialects and carrying out the inheritance of language and character heritage, and ensure the stability of economic growth.

\section{ACKNOWLEDGMENT}

Fund Project: Sichuan Province Innovation Training Program (No. 201910626084).

\section{REFERENCES}

1. Dustmann, C.1994.Speaking fluency, writing fluency and earnings of migrants $[\mathrm{J}]$. Journal of Population Economics (7):133-156.

2. Beenstock, M., Chiswick, B. R., \& Repetto, G. L.(2001). The effect of linguistic distance and country of origin on immigrant language skills: application to Israel. International Migration, 39(3),33-60.

3. Zhang Weiguo. Language as human capital, public goods and Institution: a basic analytical framework of linguistic economics [J]. Economic research, 2008 (02): 144-154

4. Mo Zaishu, Zhang Xiaoyong, Zhang Yun. 2006. Business English Research Based on linguistic economics [J]. Journal of Hunan University (SOCIAL SCIENCES) (4): 102-106

5. Lei Xiaolan. Economic value analysis of language [J]. Journal of Xi'an Jiaotong University (SOCIAL SCIENCE EDITION), 2009,29 (06): 107-110

6. Xu Xianxiang, Liu Yuyun, Xiao Zekai. Dialect and economic growth [J]. Journal of economics, 2015,2 (02): $1-32$ 
7. Liu Huiqiang. Languages and characters of ethnic minorities in Sichuan Province $[\mathrm{J}]$. Journal of Southwest Institute of Nationalities (PHILOSOPHY AND SOCIAL SCIENCES EDITION), 1984 (03): $35-38+100$ 